\title{
Polyurethanes: Design, Synthesis and Structure-Property Behavior of Versatile Materials
}

\section{Poliüretanlar: Çok Yönlü Malzemelerin Tasarımı, Sentezi ve Yapı-Performans ilișkileri}

\author{
İskender Yılgör ${ }^{*} \oplus$ and Emel Yılgör ${ }^{* \oplus}$
}

Chemistry Department and KUYTAM Surface Science and Technology Center, Koç University Istanbul, Turkey.

\section{ABSTRACT}

\begin{abstract}
Dolyurethanes are one of the most important classes of polymeric materials. This is mainly due to the availability of a very large number of inherently different starting materials that allows the design and synthesis of polyurethane based materials with a wide range of properties for numerous applications. In this short review, important physical and chemical factors and parameters that have a significant effect on the properties of polyurethanes are discussed. Critical contribution of hydrogen bonding on the structure-morphology-property behavior of these materials was emphasized by both experimental data and molecular simulation studies. Influence of the chemical structures, solubility parameters and molecular weights of the soft and hard segments on morphology and properties were discussed. Important issues regarding the reaction chemistry, synthetic method used and thermal history on structure and performance of polyurethanes were explained. We hope this article, which is prepared to celebrate the $100^{\text {th }}$ anniversary of Polymer Science, will be useful to those who are newcomers to the field, but also to the experienced researchers to better understand the structure-property behavior of polyurethanes and tailor-design novel structures for various applications.
\end{abstract}

\section{Key Words}

Polyurethane, polyurea, PU foam, elastomers, hydrogen bonding, morphology.

\section{öz}

oliüretanlar hem ticari, hem de akademik araştırmalar açısından oldukça önemli ve ilginç polimerik malzemelerdir. Bunun en temel nedeni poliüretan sentezi için gerekli çok değişik özelliklere sahip çok fazla sayıda hammaddenin bulunmasıdır. Bu sayede çeşitli uygulamalar için çok farklı yapılar ve özellikler gösteren poliüretanlar tasarlamak ve üretmek mümkündür. Bu makalede poliüretanların tasarımı ve sentezi sırasında dikkat edilmesi gereken ve polimer özelliklerine etki eden önemli fiziksel ve kimyasal değişkenler tartışımaktadır. Ayrıca hidrojen bağlarının poliüretanların yapı-morfoloji-özellik ilişkileri üzerindeki kritik etkileri hem deneysel, hem de hesaplamalı çalışmalar ile irdelenmektedir. Poliüretan yapısında bulunan yumuşak ve sert kısımların kimyasal yapılarının, çözünürlük parametrelerinin ve ortalama molekül ağırlıklarının morfoloji ve performans üzerine etkileri de ayrıntılı olarak tartışılmaktadır. Bunlara ilaveten polimerizasyon reaksiyonları sırasında dikkat edilmesi gereken kritik konuların elde edilen poliüretanların yapısı ve özellikleri üzerine etkileri de belirtilmektedir. Polimer Biliminin 100cü yılını kutlamak amacı ile hazırlanmış olan bu makalenin hem genç, hem de deneyimli araştırmacılara poliüretanların yapısal tasarımları ve sentezleri sırasında göz önünde bulundurulması gereken önemli parametreler ve elde edilen polimerlerin yapı-performans ilişkileri ve uygulamaları konularında yardımcı olacağını umuyoruz.

\section{Anahtar Kelimeler}

Poliüretan, poliüre, PU köpük, elastomerler, hidrojen bağı, morfoloji.

Bu makale Orta Doğu Teknik Üniversitesi başta olmak üzere Türkiye'nin pek çok üniversitesinde modern polimer biliminin yerleşmesine öncülük eden Prof. Dr. Bahattin M. Baysal'ın anısına ithaf edilmiştir.

Article History: Received: Aug 28, 2020; Revised: Sep 20, 2020; Accepted: Oct 20, 2020; Available Online: Oct 20, 2020. .DOI: https://doi.org/10.15671/hjbc.809902

Correspondence to: E. Yılgör, Chemistry Department and KUYTAM Surface Science and Technology Center, Koç University Istanbul, Turkey. E-Mail: iyilgor@ku.edu.tr 


\section{INTRODUCTION}

olyurethanes (PU) are one of the most important classes of synthetic polymers, where availability of a very broad range of starting materials allows polymer scientists and engineers to design and synthesize novel materials with diverse properties and applications [1-8]. Although "polyurethane" is used as the general name, this class of polymeric materials also include polyureas a major role in the discovery of polyurethanes by Otto Bayer in 1937 [13, 14], who was trying to produce synthetic fibers similar to polyamides (Nylon) discovered by Carothers and commercialized by Du Pont $[15,16]$. In their studies at I. G. Farben, Leverkusen, Germany, Bayer and co-workers used both aliphatic and aromatic diisocyanates and low molecular weight diols and diamines to produce polyuret-

$$
\begin{aligned}
& \mathbf{R}-\mathrm{N}=\mathrm{C}=\mathrm{O}+\mathrm{HO}-\mathbf{R}_{1} \rightarrow \mathbf{R}-\stackrel{\mathrm{H}}{\mathrm{N}}-\stackrel{\mathrm{O}}{\mathrm{C}}-\mathrm{O}-\mathbf{R}_{1}
\end{aligned}
$$

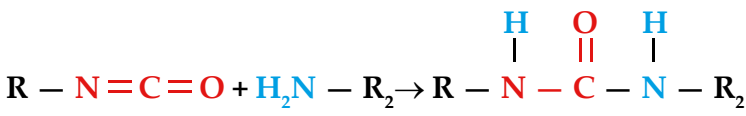

Figure 1. Urethane (1) and urea (2) formation reactions.

and polyurethaneureas. As shown in Figure 1, urethane and urea linkages are formed by the addition reactions of alcohols and amines to isocyanates respectively, where $\mathrm{R}$ can be an aliphatic or aromatic moiety. Detailed information on the nature of these reactions and reaction mechanisms are provided in several excellent reviews [6, 7-10]. A brief discussion will also be provided in the next session.

One of the most important properties of the urethane and urea linkages is their ability to form strong intermolecular hydrogen bonding (Figure 2), which influences their morphology and overall physical properties significantly $[11,12]$.

As shown in Figure 2, compared to the urethane groups, which usually make monodentate hydrogen bonding, urea groups can make stronger, bidentate hydrogen bonding. Values of maximum hydrogen bond energies for urethane and urea groups were determined by quantum mechanical calculations and were reported to be 58.5 and $46.5 \mathrm{~kJ} /$ mol, respectively [11]. Interestingly, ability of the urethane and urea groups to form strong hydrogen bonding played hanes and polyureas, for which a patent application was made on Nov. 13, 1937 and granted on Dec. 7, 1942. However, unlike polyamides, which are thermally stable up to around $270^{\circ} \mathrm{C}$ for melt spinning, these materials were not melt processable due to the thermal decomposition of urethane and urea linkages above $200^{\circ} \mathrm{C}$ [17]. Later on, during the Second World War (1940-1945) by the introduction of oligomeric diols it was possible to produce processable PU elastomers, foams, adhesives and coatings by Otto Bayer at I. G. Farben, Germany and others at ICl, England and Du Pont, USA [18].

After these initial efforts and important achievements, dramatic developments have taken place in PU science and technology after 1950s, which is still continuing. As summarized below, We believe there are several critical reasons/factors for the widespread interest in PUs by both academic and industrial scientists, which still leads to the development of new products and applications.

- $\quad$ One of the most important factors is the commercial availability of a very large number of starting materials, including aliphatic and aromatic diisoc- 


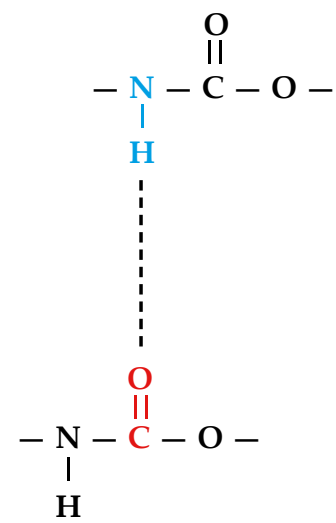

Monodentate
Hydrogen bonding
(Urethane)<smiles>CNC(=O)NC[IH]C</smiles><smiles>CNC(=O)NC</smiles>

Bidentate

Hydrogen bonding (Urea)

Figure 2. Schematic description of monodentate and bidentate hydrogen bonding between urethane and urea linkages.

yanates and polyisocyanates, low molecular weight diols and diamines (chain extenders), together with high molecular weight or oligomeric diols, polyols, and diamines (soft segment oligomers). This allows polymer scientists and engineers to design and synthesize PUs with almost infinite number of compositions, morphologies and properties. For example, by using difunctional starting materials it is possible to make linear thermoplastic elastomers with a wide range of properties for fiber and film applications. On the other hand, by employing trifunctional reactants it is possible to prepare crosslinked PUs, such as; flexible or rigid foams [8], cast rubbers/elastomers, adhesives and coatings [3-5], which are highly desirable for various applications in many different fields.

- Another important factor is well understood chemistry of urethane and urea formation reactions, which have been extensively investigated over the past 50 years $[3,7]$. Urethane formation reactions proceed at moderate temperatures $\left(50-100^{\circ} \mathrm{C}\right)$ and usually under the action of a catalyst $[7,9]$, whereas urea formation reactions take place almost instantaneously at room temperature [19, 20].

- $\quad$ Strong hydrogen bonding character of the urethane and urea linkages with each other and/or with different functional or polar groups makes the investigation of structure-morphology-property behavior of these materials highly interesting for scientists $[11,21]$.

- $\quad$ From industrial point of view, the major driving force for the interest in PUs is the wide range of applications of these materials in many diversified fields, which includes industries such as; automo- 
tive, aerospace, electronics, textiles, construction, paints and protective coatings, medicine, furniture, appliances, footwear, sporting goods, packaging, adhesives and sealants, etc. Another critical factor is the recyclability of polyurethanes through chemical methods, such as hydrolysis or glycolysis $[22,23]$, which is desired to prevent environmental pollution and sustainability. Currently global polyurethane market is worth about 55-60 billion US dollars (a great majority of it being in flexible and rigid foams) and is expected to grow about $6 \%$ annually according to several market reports [24-26].

In this review a comprehensive summary on general aspects and critical issues of polyurethane science and technology will be provided. This will include (i) type, nature and properties of a wide range of commercially available starting materials, (ii) critical aspects of the chemistry of urethane and urea formation reactions, (iii) thermodynamic considerations regarding microphase separation and PU morphology. After this general introduction, a brief discussion will be provided on the preparation and properties of PU foams, which will be followed by detailed discussion on the design, synthesis, structure-morphology-property behavior of linear, segmented, thermoplastic polyurethanes and polyureas (TPUs).

\section{Important factors and critical issues regarding PU science and technology \\ 1.1. Availability of a wide range of starting materials with different properties}

Linear or crosslinked PUs are generally produced by using 3 basic classes of reactants. These are; (i) isocyanates, (ii) hydroxyl or amine terminated soft segment oligomers, and (iii) low molecular weight diol or diamine chain extenders. Polyurethane formation reactions are step-growth polymerization reactions [27], therefore, in order to produce high molecular weight linear PUs one needs to utilize perfectly difunctional $(f=2)$ starting materials, whereas for crosslinked or network systems, polyfunctional starting materials ( $f>2$ ) are needed. A list of most widely used and commercially available diisocyanates and soft segment oligomers for PU synthesis are provided in Tables 1 and 2.

Table 1. Chemical structures of diisocyanates commonly used in PU synthesis.

\begin{tabular}{|c|c|c|}
\hline Diisocyanate & Chemical structure & Code \\
\hline Hexamethylene & $\mathrm{OCN}-\left(\mathrm{CH}_{2}\right)_{6}-\mathrm{NCO}$ & HDI \\
\hline Bis(4-isocyanatocyclohexyl) & & HMDI \\
\hline Isophorone & & IPDI \\
\hline 1,4-Phenylene & & PPDI \\
\hline 2,4-Tolylene & & TDI \\
\hline 4,4'-Methylenediphenyl & & MDI \\
\hline
\end{tabular}


Table 2. Types of soft segment oligomers commonly used in PU synthesis.

\begin{tabular}{|c|c|c|}
\hline Family name & $\begin{array}{c}\text { Chemical structure of } \\
\text { the repeat unit }\end{array}$ & Types \\
\hline \multirow{3}{*}{ Aliphatic Polyethers } & \multirow{3}{*}{$\left.\mathrm{HO}-\left(\mathrm{CH}_{2}\right)_{x} \mathrm{O}\right)_{n}-\mathrm{H}$} & Poly(ethylene oxide) (PEO) \\
\hline & & Poly(propylene oxide) (PPO) \\
\hline & & Poly(tetramethylene oxide) (PTMO) \\
\hline \multirow{4}{*}{ Aliphatic Polyesters } & 00 & Poly(ethylene adipate) \\
\hline & \|\| & Poly(butylene adipate) \\
\hline & $\mathrm{H}\left(\mathrm{OR}_{1} \mathrm{OCR}{ }_{2} \mathrm{C}\right)_{\mathrm{n}}-\mathrm{R} 1 \mathrm{OH}$ & Poly(neopentyl adipate) \\
\hline & & Polycaprolactone (PCL) \\
\hline \multirow{3}{*}{ Aliphatic Polycarbonates } & \multirow{3}{*}{$\|_{\mathrm{HO}(\mathrm{ROCO})_{n}-\mathrm{ROH}}$} & Poly(propylene carbonate) \\
\hline & & Poly(butylene carbonate) \\
\hline & & Poly(hexamethylene carbonate \\
\hline \multirow{5}{*}{ Silicones } & $\mathrm{CH}_{3} \quad \mathrm{CH}_{3}$ & \multirow{5}{*}{ Polydimethylsiloxane (PDMS) } \\
\hline & $1 \quad 1$ & \\
\hline & $\mathrm{HO}-\mathrm{R}-(\mathrm{Si}-\mathrm{O})_{n}-\mathrm{Si}-\mathrm{R}-\mathrm{OH}$ & \\
\hline & l 1 & \\
\hline & $\mathrm{CH}_{3} \quad \mathrm{CH}_{3}$ & \\
\hline
\end{tabular}

Although only difunctional starting materials are described in these tables, their trifunctional analogs (both isocyanates and the oligomers) are also commercially available. Furthermore, soft segment oligomers with molecular weights from 500 to $5,000 \mathrm{~g} / \mathrm{mol}$ are available, although 1,000-2,000 g/mol are most popular. A large number of linear or branched aliphatic diols (HO-R$\mathrm{OH}$ ) or triols and diamines $\left(\mathrm{H}_{2} \mathrm{~N}-\mathrm{R}-\mathrm{NH}_{2}\right)$ or triamines are also available as chain extenders, most popular chain extenders have 2 to 6 carbon atoms in their backbone.
Structures and compositions of PUs are generally described by the type and amount of hard and soft segments. Hard segments (HS) are formed by the reaction of isocyanates with chain extenders, whereas the organic backbone of the oligomers used constitutes the soft segments (SS). This is schematically described in Figure 3 for linear PUs. As will be discussed in detail later, chemical structure, average molecular weight and amount of SS and chemical structure (urethane or urea), molecular weight and amount of HS in the polymer play critical roles in determining the morphology, properties and performance of PUs [1].

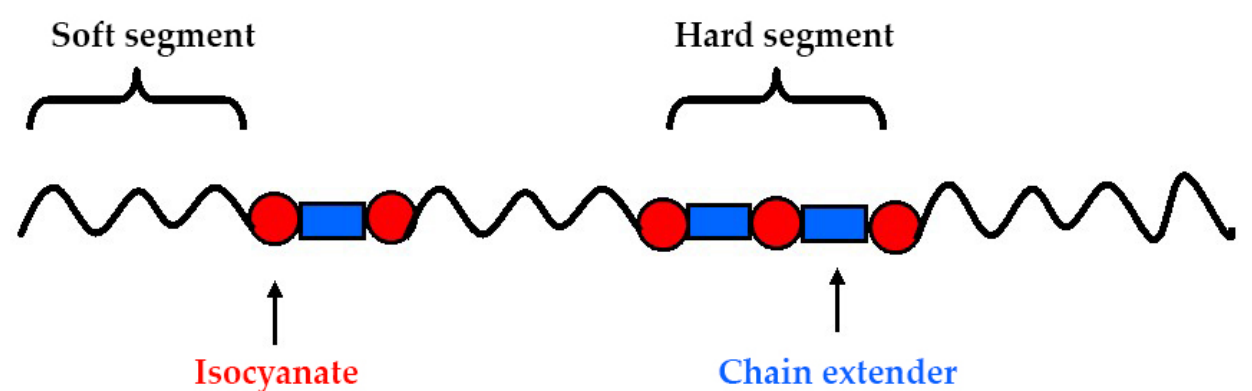

Figure 3. Schematical description of the soft and hard segments in a polyurethane chain. 
Table 3. Relative reactivities of aromatic isocyanates with different active hydrogen compounds.

\begin{tabular}{|c|c|c|}
\hline Active hydrogen compound & Chemical structure & Relative reaction rate at $25^{\circ} \mathrm{C}$ \\
\hline Primary aliphatic amine & $\mathrm{R}-\mathrm{NH}_{2}$ & 100,000 \\
\hline Secondary aliphatic amine & $\mathrm{R}_{2}-\mathrm{NH}$ & 40,000 \\
\hline Primary aromatic amine & $\mathrm{Ar}-\mathrm{HN}_{2}$ & 250 \\
\hline Water & $\mathrm{H}-\mathrm{O}-\mathrm{H}$ & 100 \\
\hline Primary aliphatic alcohol & $\mathrm{R}-\mathrm{CH}_{2}-\mathrm{OH}$ & 100 \\
\hline Secondary aliphatic alcohol & $\mathrm{R}_{2} \mathrm{CH}-\mathrm{OH}$ & 30 \\
\hline Tertiary aliphatic alcohol & $\mathrm{R}_{3}-\mathrm{C}-\mathrm{OH}$ & 0.5 \\
\hline Urethane & $\mathrm{R}-\mathrm{NH}-\mathrm{COOR}$ & 0.3 \\
\hline
\end{tabular}

\subsection{Critical aspects of the chemistry of urethane and urea formation reactions}

Reactivities of isocyanates with alcohols and amines strongly depend on the nucleophilicity of the reactants and electrophilicity of the isocyanate used. Relative reactivities of aromatic isocyanates with different types of active hydrogen compounds at $25^{\circ} \mathrm{C}$ are given in Table 3 [8]. Due to much higher nucleophilicity of amines compared to alcohols, urea formation reactions are much faster than urethanes and take place instantaneously at room temperature. Primary amines and alcohols react much faster than their secondary analogs due to their higher nucleophilicity. Similarly, aromatic isocyanates, which are more electrophilic than their aliphatic counterparts react faster with alcohols as shown in Figure 4.

While polyurethanes based on aromatic diisocyanates can be reacted and synthesized at moderate temperatures $\left(50-100^{\circ} \mathrm{C}\right)$ without a catalyst, aliphatic isocyanate-alcohol reactions need catalysis at similar temperatures $[1,7,9]$. Various triamines and/or metal salts are

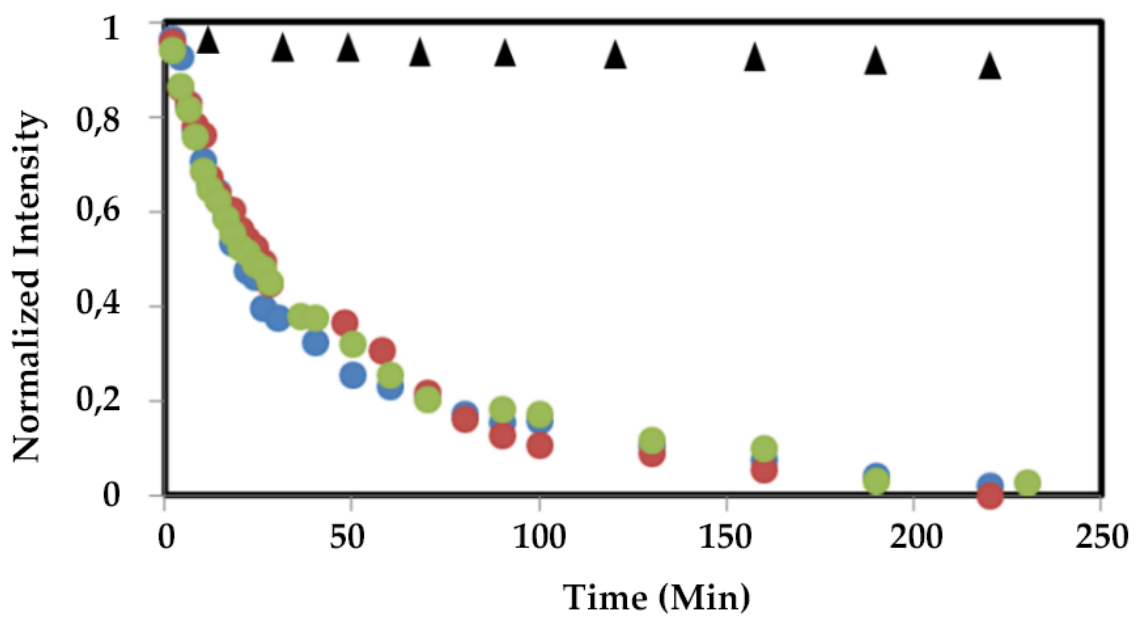

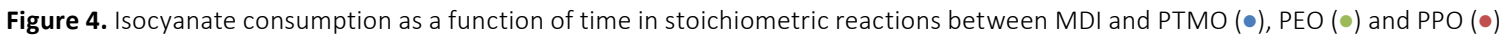
and $\mathrm{HMDI}$ and PTMO $(\mathbf{\Delta})$ in DMF at $25^{\circ} \mathrm{C}$, followed by FTIR spectroscopy. (All oligomers have $\mathrm{Mn}=1000 \mathrm{~g} / \mathrm{mol}$ and all are primary OH terminated. No catalyst is present in the system). 
used as catalysts for aromatic isocyanates only when extremely fast reactions rates are required, such as in $\mathrm{PU}$ foam formation [8] or in reaction injection molding (RIM) $[28,29]$.

Addition reactions of alcohols and amines to isocyanates to produce urethane and urea linkages respectively are second order reactions [7]. However, as the reaction proceeds and concentration of the urethane linkages in the system increases, the $\mathrm{N}-\mathrm{H}$ groups on urethane linkages also start reacting with the isocyanate groups as shown in Figure 5, to produce allophanate groups, although their reactivities are low, as shown in Table 3. However, allophanate reactions become significant if a catalyst is used during the reactions $[30,31]$.

This leads to deviation from second order to higher order kinetics [9] and more importantly results in the formation of branched polymers. If the reactions are conducted at high temperatures and under very efficient catalysts, allophanate groups can further react with isocyanate groups, eventually leading to the formation of crosslinked products [30,31]. Such side reactions are not desirable in the synthesis of linear, segmented thermoplastic polyurethanes (TPU), but highly preferable in crosslinked foams and elastomers.

\subsection{Thermodynamic considerations regarding microphase separation}

Polymer morphology, which can simply be described as the arrangement or microphase structure, of the polymer chains (in case of PU the hard and soft segments) in the solid state, plays a critical role in determining polymer properties [1]. Morphologies of block and segmented copolymers strongly depend on the miscibility or compatibility of the individual blocks. To obtain optimum performance, it is desirable to have inherently incompatible blocks, which phase separate from each other, just like oil and water mixtures. Interestingly, existence of a covalent bond between the blocks in the copolymer prevents complete phase separation and therefore these copolymers display microphase separated morphologies, which strongly influence their properties, as schematically shown in Figure 6.

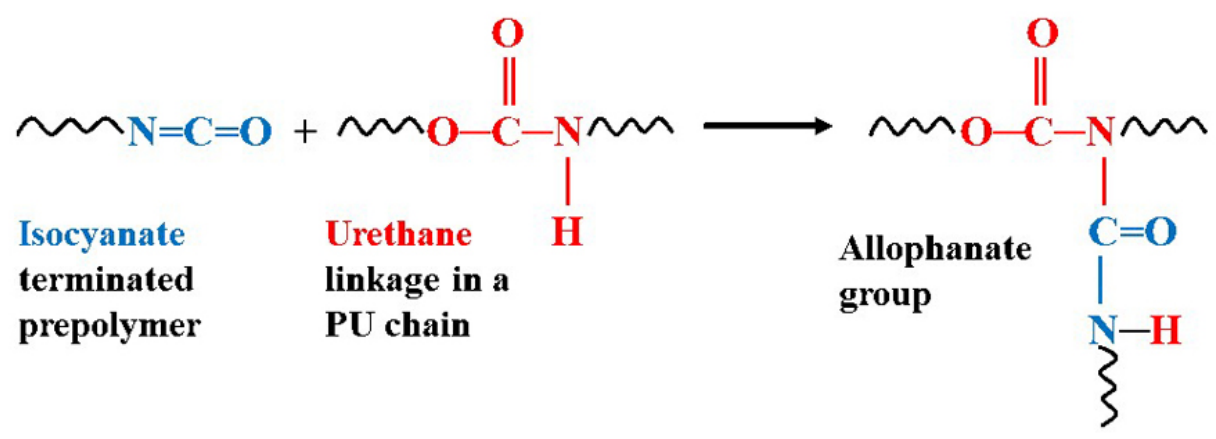

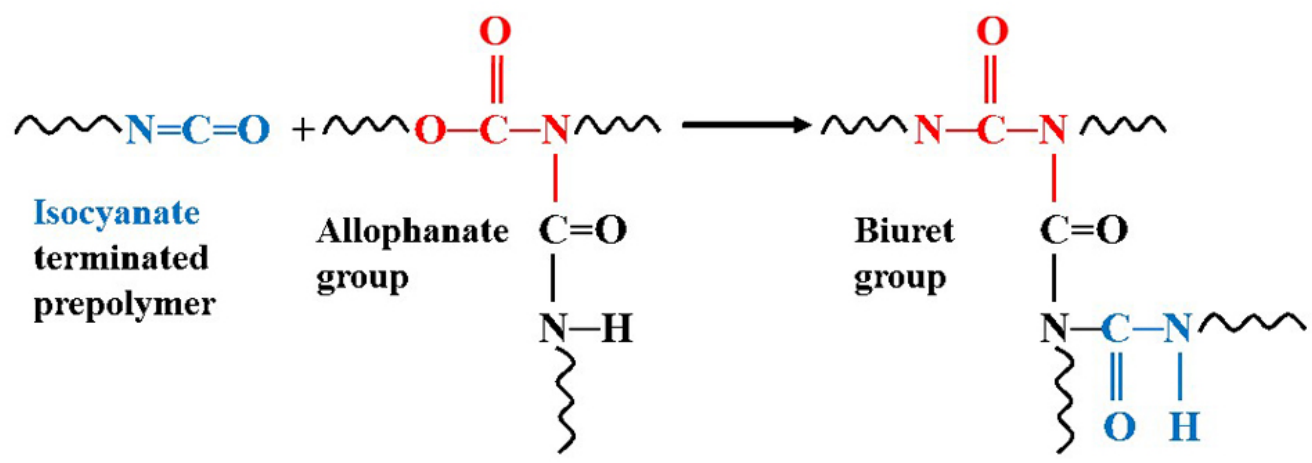

Figure 5. Side reactions observed during the synthesis of polyurethanes. 


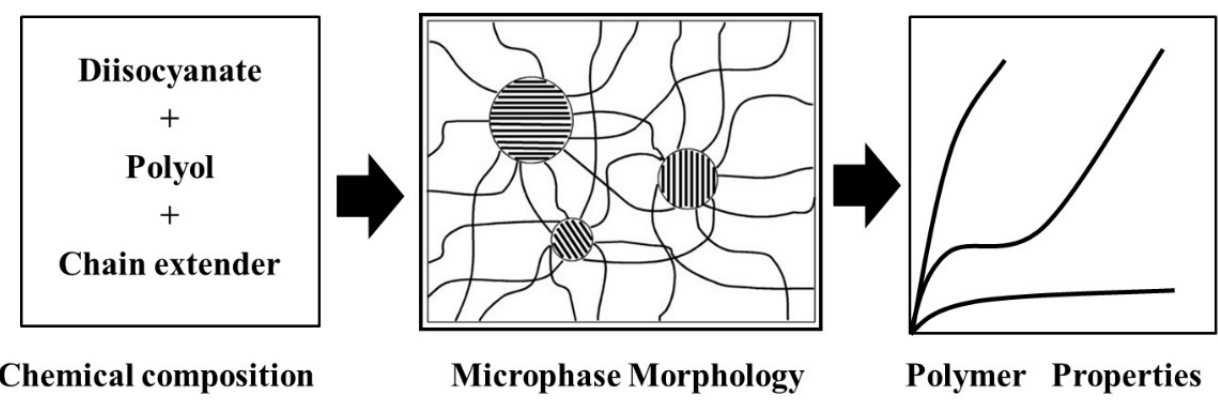

Figure 6. Schematic representation of the structure-morphology-property relationship in PUs.

Miscibility or compatibility of a mixture of two different polymers can be predicted by Gibbs free energy of mixing $\left(\Delta G_{\text {mix }}\right)$ relationship given in (Eq. 3). If $\Delta G_{\text {mix }}$ is negative, the mixture will be thermodynamically compatible.

$\Delta \mathrm{G}_{\text {mix }}=\Delta \mathrm{H}_{\text {mix }}-\mathrm{T} \Delta \mathrm{S}_{\text {mix }}$

Fundamental thermodynamic model developed by Flory and Huggins (FH) for polymer solutions (Eq. 4, 5, 6) $[27,32,33]$ was later modified to describe the miscibility of polymer blends and block copolymers [34, 35]. Eq. 4 is the general $\mathrm{FH}$ relationship that describes the miscibility of two component ( $\mathrm{A}$ and $\mathrm{B}$ ) polymeric systems (blends or copolymers), by combining the corresponding enthalpic and entropic contributions to mixing, given by Eqs. 5 and 6 respectively, where $n_{A}$ and $n_{B}$ are the number of moles of component $A$ and $B$ respectively, while $\phi_{A}$ and $\phi_{B}$ are their respective volume fractions. $R$ is the molar gas constant and $T$ is the absolute temperature [36].

$$
\begin{aligned}
& \Delta \mathrm{G}_{\text {mix }}=R T\left(\mathrm{n}_{A} \ln \phi_{A}+n_{B} \ln \phi_{B}+n_{A} \phi_{B} x_{A B}\right) \\
& \Delta H_{\text {mix }}=R T n_{A} \phi_{B} x_{A B} \\
& \Delta S_{\text {mix }}=R T\left(n_{A} \ln \phi_{A}+n_{B} \ln \phi_{B}\right)
\end{aligned}
$$

The enthalpic term contains the parameter $(\chi)$, known as the interaction or "chi" parameter, which relates to the degree of interaction of the two components present in the system. This parameter is also correlated to the Hildebrand solubility parameters $\left(\delta_{A}\right.$ and $\left.\delta_{B}\right)$ of the two components in the mixture as given by Eq. 7, where $V$ is the average molar volume of the repeat units of the copolymer.
$\chi_{A B}=\left(\delta_{A}-\delta_{B}\right)^{2} V / R T$

In general, if the chi parameter $(\chi)$ is large (or if the solubility parameter difference between hard and soft segment is large) this indicates strong immiscibility between the segments and microphase separation in the system. If chi parameter is small and close to zero, it indicates good compatibility between the two components and hence phase mixing. Therefore, to synthesize a PU (or a block copolymer) that displays good microphase separation, soft and hard segments with highly different solubility parameters need to be selected. Values of the solubility parameters for model phenylcarbamate (urethane) and phenylurea (urea) hard segments calculated using group contribution method and the experimental solubility parameters of various soft segments widely used in PU synthesis are provided in Table 4.

By comparing the solubility parameter values given in Table 4, PEO based PUs are expected to show the highest phase mixing, while PDMS based polyureas are expected to display excellent microphase separation. This has also been demonstrated experimentally and has been reported in the literature extensively $[1,4,5,19$, 42-45].

\subsection{Polyurethane foams}

Although polyurethane foams commercially command a much broader market volume and numerous applications, it is a very specialized and a rather complex technology [8]. Therefore, here we will only provide the basic features of PU foam technologies. Our main discussion in this article will be on linear, segmented, thermoplastic polyurethanes (TPUs). 
Table 4. Hildebrand solubility parameter $(\delta)$ values for various hard and soft segments.

\begin{tabular}{|c|c|c|c|}
\hline Segment & Chemical structure & $\delta\left(\mathrm{J} / \mathrm{cm}^{3}\right)^{1 / 2}$ & Reference \\
\hline 1,4-Phenylenedicarbamate & $\begin{array}{ccc}\mathrm{O} & \mathrm{H} & \mathrm{H} \\
\| & \mathrm{I} & \mathrm{O} \\
-\mathrm{C}-\mathrm{N} & \mathrm{I} & \| \\
-\mathrm{N}-\mathrm{C}-\mathrm{O}-\end{array}$ & 30.8 & Calculated [36] \\
\hline 1,4-Phenylenediurea & 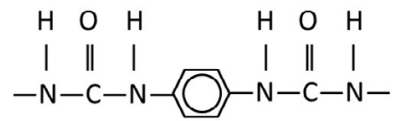 & 37.9 & Calculated [36] \\
\hline Polyethylene oxide & {$\left[\mathrm{CH}_{2} \mathrm{CH}_{2}-\mathrm{O}\right]_{n}$} & 20.2 & {$[37]$} \\
\hline Polypropylene oxide & {$\left[\mathrm{CH}\left(\mathrm{CH}_{3}\right) \mathrm{CH}_{2}-\mathrm{O}\right]_{n}$} & 18.9 & [38] \\
\hline Polytetramethylene oxide & {$\left[\mathrm{CH}_{2} \mathrm{CH}_{2} \mathrm{CH}_{2} \mathrm{CH}_{2}-\mathrm{O}\right]_{n}$} & 17.6 & [39] \\
\hline Polycaprolactone & {$\left[\left(\mathrm{CH}_{2}\right)_{5}-\mathrm{CO}-\mathrm{O}\right]_{n}$} & 17.0 & [40] \\
\hline Polydimethylsiloxane & {$\left[\mathrm{Si}\left(\mathrm{CH}_{3}\right)_{2}-\mathrm{O}\right]_{n}$} & 15.6 & [41] \\
\hline
\end{tabular}

A polymeric foam is a highly porous substance, where tiny air pockets are homogeneously distributed in a polymeric matrix. Average pore size in a polymeric foam may vary from microns to millimeters. PU foams are divided in two main classes, which are (i) rigid foams and (ii) flexible foams. As the names imply, rigid foams are hard and rigid, while flexible foams are soft and flexible at room temperature. Rigid PU foams are mainly used in packaging, in insulation panels of the home appliances and construction and transportation industries. On the other hand, flexible PU foams find applications in furniture, bedding and seating in home and transportation. When designing a PU foam, critical issues that need to be considered are (i) foam type (rigid or flexible), (ii) pore type (open or closed), (iii) average pore size, (iv) foam density, and (iv) mechanical properties.

Since they are based on the same chemistry, basic formulations used for both rigid and flexible PU foam systems are very similar and mainly consist of (i) a polyisocyanate, (ii) polyol, (iii) surfactant, (iv) blowing agent, and (v) catalyst [8]. By proper selection of each component and overall foam composition, it is possible to tailor design PU foams with desired properties and performance. Since the end product is crosslinked, PU foam formulations are prepared as two-part systems that al- lows long term storage. Part A consists of polyisocyanate, whereas Part B contains polyol, surfactant, blowing agent and catalyst. PU foam products are prepared by mixing both components well, pouring the mixture into a mold or space to be filled and curing them under ambient conditions or at elevated temperatures.

Regarding the ingredients used in PU foam production, trifunctional polyisocyanates are generally derived from aromatic (TDI or MDI) diisocyanates due to their availability and higher reactivity compared to aliphatic polyisocyanates [8]. Multifunctional polyols employed are mainly based on aliphatic polyethers (ethylene oxide and propylene oxide), aliphatic polyesters or polycarbonates, although recently bioderived polyols are also becoming highly popular [46]. Main difference between the polyols used for flexible and rigid foams lie in their average molecular weights, where low molecular weight polyols $(<1000 \mathrm{~g} / \mathrm{mol})$ are used in rigid foams and high molecular weight polyols (>2000 g/mol) are employed in flexible foam formulations [8]. Surfactants are generally PPO-PEO or PDMS-polyether based oligomeric surface-active species and are used to control the homogeneity of the foaming process, pore type, average pore size and pore distribution in the foam [47]. Blowing agents are low boiling inert organic solvents, 
such as pentane, isopentane or various fluorocarbons, which evaporate during the exothermic foaming process to produce the porous foam structure. Sometimes water is also used as a foaming agent, since it produces carbon dioxide gas when it reacts with the isocyanate group. Furthermore, the amine formed in the reaction immediately reacts with the isocyanate groups to produce urea linkages, as shown in the reaction scheme below, which also toughens the foam.

$\mathrm{R}-\mathrm{NCO}+\mathrm{H}_{2} \mathrm{O} \rightarrow \mathrm{R}-\mathrm{NH}-\mathrm{COOH} \rightarrow \mathrm{R}-\mathrm{NH}_{2}+\mathrm{CO}_{2}$ $\mathrm{R}-\mathrm{NH}_{2}+\mathrm{R}_{1}-\mathrm{NCO} \rightarrow \mathrm{R}-\mathrm{NHCONH}-\mathrm{R}_{1}$

\section{Linear, segmented, thermoplastic polyurethanes and polyureas}

Although flexible and rigid PU foams constitute the largest volume of commercial products, academically the most widely investigated PU systems are linear, segmented PUs, which are generally termed as thermoplastic polyurethanes or TPUs $[1,6]$. TPUs also find numerous applications as elastomeric textile fibers [2] biomaterials [5], paints and coatings, [48] films and semi-permeable membranes [49]. In addition to their various specialty or niche applications, widespread interest in TPUs mainly arises due to their interesting structure and composition dependent microphase morphologies and properties [1].

As shown schematically in Figure 3, a TPU is a linear polymer chain consisting of covalently bonded, alternating hard and soft segment repeat units. Soft segments (SS) are oligomers with glass transition temperatures $\left(T_{g}\right)$ well below room temperature (generally -50 to $-120^{\circ} \mathrm{C}$ ). Hard segments (HS), which are usually produced by the chemical combination of a diisocyanate and a diol or diamine chain extender, to produce strongly hydrogen bonding urethane or urea hard segments respectively, have $T_{g}$ values or melting points (if crystalline) well above room temperature (generally $>100^{\circ} \mathrm{C}$ ). Depending on their chemical compositions and microphase morphologies TPUs may display properties ranging from rigid and tough plastics to soft and strong elastomers. Availability of very large number of starting materials with different chemical structures, solubility parameters and properties allow polymer scientists to tailor design almost infinite number of TPUs. Critical chemical and physical parameters that need to be considered when designing TPUs are summarized below.
- Structure and symmetry of the diisocyanate,

- $\quad$ Type (urethane or urea), chemical structure and chain length of the hard segment,

- $\quad$ Average molecular weight, structure, and solubility parameter of the soft segment,

- Soft and hard segment content of TPU,

- Method of TPU synthesis (one step versus two step polymerization reaction)

- Thermal history or annealing time and temperature.

Influence of these parameters on TPU structure, morphology and properties will be discussed comprehensively. We hope this will help polymer scientists working in the area to tailor-design TPUs and better understand structure-morphology-property behaviors of these materials.

\subsection{Influence of hydrogen bonding and diisocyanate symmetry on TPU morphology and properties}

Influence of the hard segment symmetry and strength of hydrogen bonding on TPU morphology and properties were investigated using model polyurethane and polyurea segmented copolymers, prepared by the stoichiometric reactions of various diisocyanates with poly(tetramethylene oxide)glycol (PTMO1k) oligomer, which had an average molecular weight of $1000 \mathrm{~g} / \mathrm{mol}$ [50-52]. TPUs thus prepared had uniform hard segments, which consisted of the backbone of the diisocyanate $(R)$ used and the urethane or urea end groups linked to it, as shown in Figure 7.

Diisocyanate backbone structures shown on the top row in Figure 7 are symmetrical, whereas the ones in the bottom are unsymmetrical, due to the kinked substitution in 1,3-phenylene and the twisted rings due to the tetrahedral structure of the methylene carbon. Model TPUs were characterized by a variety of techniques, which included Fourier transform infrared spectroscopy (FTIR), atomic force microscopy (AFM), small angle $x$-ray scattering (SAXS), dynamic mechanical analysis (DMA) and stress-strain tests. Computational studies were also carried out to better understand the influence of molecular level hydrogen bonding on the organization of polymer chains and on TPU morphology and properties [11, 12, 53].

It is important to note that, model polyurethanes prepared from asymmetric diisocyanates (MPDI, HMDI and MDI) were all sticky materials and did not form solid 


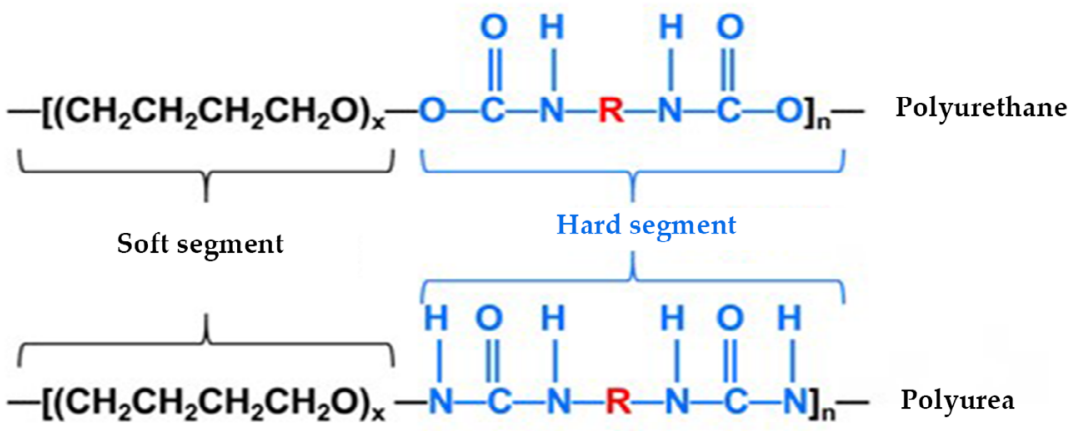

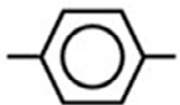

1,4-phenylene

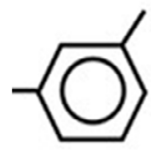

1,3-phenylene

$$
-\left(\mathrm{CH}_{2}\right)_{6}-
$$

1,6-hexamethylene

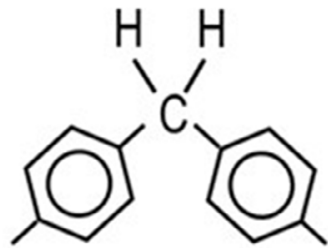

4,4'-diphenylmethane

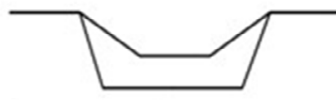

1,4-transcyclohexane

Figure 7. Model segmented PTMO-urethane and PTMO-urea copolymers with uniform hard segments obtained by the stoichiometric reactions of various diisocyanates and PTMO1k and the chemical structures of the diisocyanate backbones (R).

films at room temperature, while polyurethanes based on symmetrical diisocyanates (PPDI, HDI and CHDI) all formed strong solid films. On the other hand, all polyurea copolymers formed good solid films at room temperature, regardless of the diisocyanate structure. Hard segment contents, microphase morphology, interdomain spacings calculated from SAXS and ultimate tensile strengths of all model TPUs are provided in Table 5. These results clearly demonstrate critical influence of hydrogen bond strength (bidentate urea being much stronger than monodentate urethane) and hard seg- ment symmetry on microphase morphology and tensile properties of TPUs, which were also strongly supported by AFM and DMA results, as discussed below.

Surface AFM images of model TPUs, which are provided in Figure 8, clearly show the microphase morphologies of materials based on symmetrical diisocyanates, where fibrillar hard segment networks are clearly visible in the amorphous soft segment matrix. AFM images of symmetric MDI (shown), HMDI and MPDI based TPUs were featureless, clearly indicating complete phase mixing between the hard and the soft segments [51, 52, 

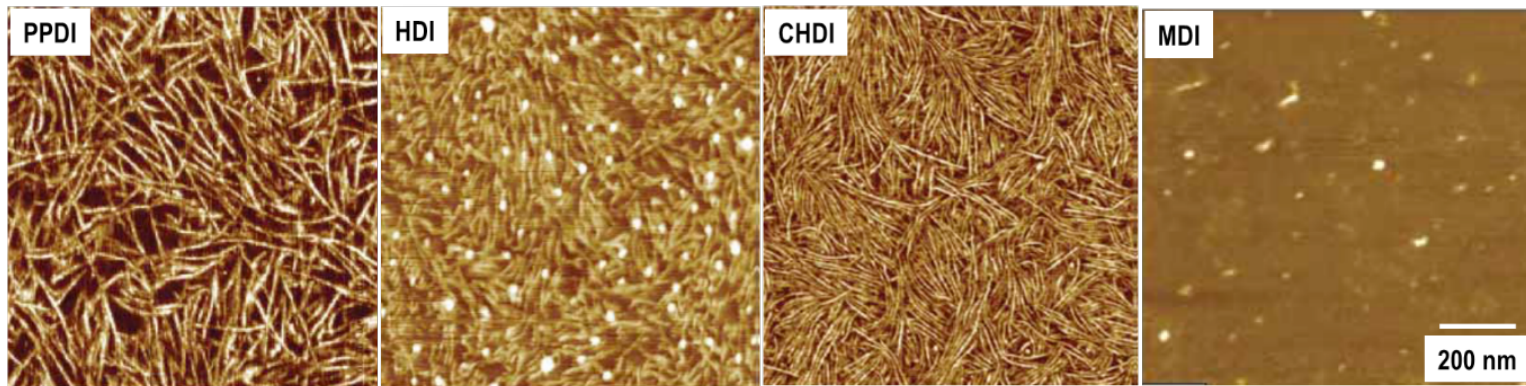

Figure 8. Tapping mode AFM phase images of model polyurethanes prepared by stoichiometric reactions of PTMO1k and various diisocyanates [54].

54]. Regardless of the diisocyanate structure, all model polyureas displayed microphase morphologies as shown in Figure 9.

These observations were supported by SAXS studies, where interdomain spacings calculated from SAXS interference peaks are provided in Table 5 for all TPUs [52]. SAXS did not show presence of any hard segment domains or microphase separation in polyurethanes based on MDI, HMDI and MPDI. It is also important to note that very strong hydrogen bonding between urea hard segments results in much tighter packing of the hard segments and much shorter interdomain spacing when compared with analogous polyurethanes.

As shown in Figure 10, DMA results also clearly indicate the significant effect of hydrogen bond strength and diisocyanate symmetry on modulus-temperature behavior of these model systems, especially on the rubbery plateau [51]. As expected, all TPUs show a very sharp soft segment (PTMO) glass transition around $-70^{\circ} \mathrm{C}$. Asymmetric MPDI-Urethane show the sharpest drop in the storage modulus, and an extremely short rubbery pla-

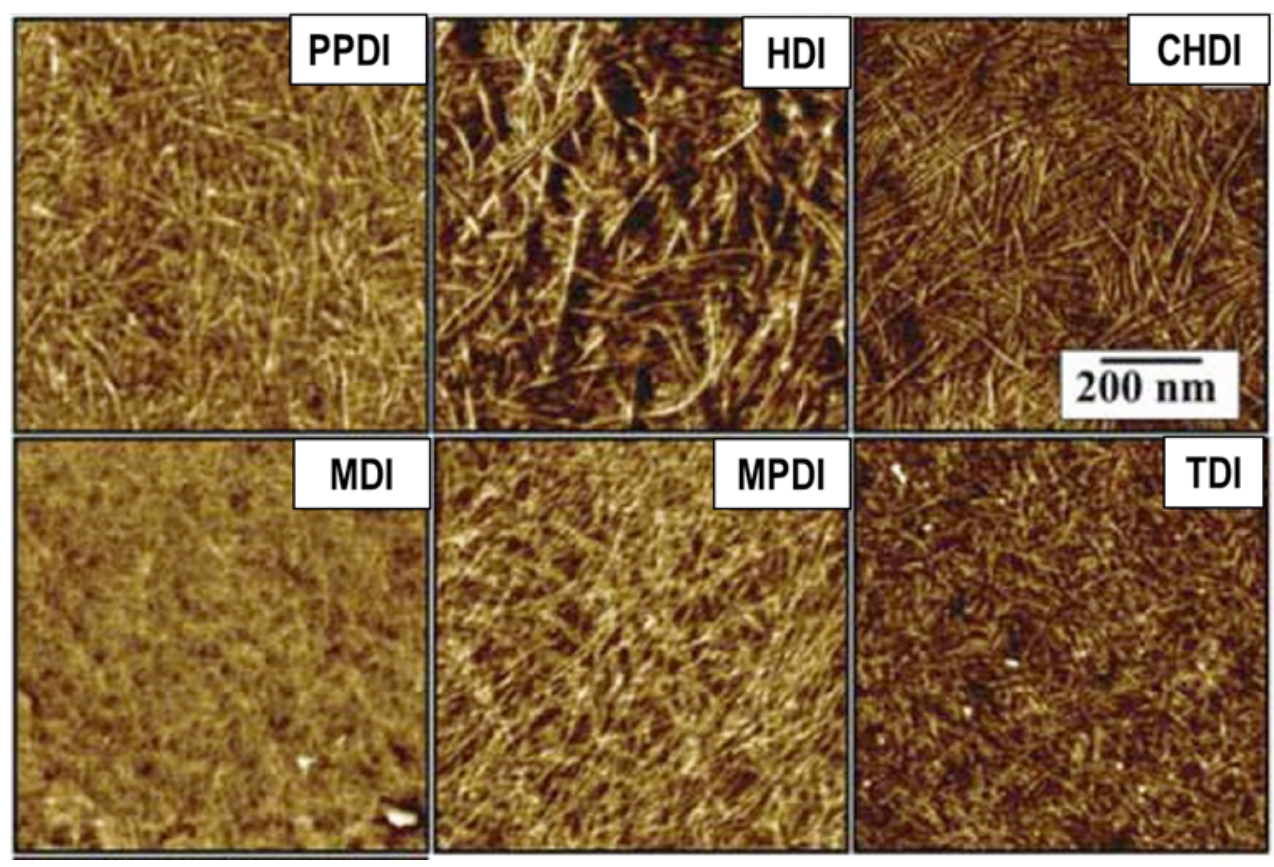

Figure 9. Tapping mode AFM phase images of model polyurethanes prepared by stoichiometric reactions of PTMO1k and various diisocyanates [54]. 
Table 5. Hard segment content, nature of the microphase morphology, interdomain spacings calculated from SAXS and ultimate tensile strengths of model TPUs.

\begin{tabular}{ccccc}
\hline $\begin{array}{c}\text { Sample } \\
\text { Description }\end{array}$ & HS Content (Wt \%) & Microphase separation & Interdomain spacing (A) & $\begin{array}{c}\text { Ultimate Tensile } \\
\text { Strength (MPa) }\end{array}$ \\
\hline PPDI-Urethane & 14.1 & Yes & 185 & 14.1 \\
\hline HDI-Urethane & 14.7 & Yes & 189 & 22.8 \\
\hline CHDI-Urethane & 14.2 & Yes & 112 & 23.0 \\
\hline MPDI-Urethane & 14.1 & No & -- & -- \\
\hline MDI-Urethane & 18.5 & No & -- & -- \\
\hline HMDI-Urethane & 19.2 & No & -- & 19.5 \\
\hline PPDI-Urea & 12.7 & Yes & 55 & 24.7 \\
\hline HDI-Urea & 13.2 & Yes & 80 & 30.0 \\
\hline CHDI-Urea & 13.1 & Yes & 79 & 5.40 \\
\hline MPDI-Urea & 12.7 & Yes & 61 & 16.9 \\
\hline MDI-Urea & 18.5 & Yes & 75 & 19.6 \\
\hline HMDI-Urea & 19.3 & Yes & 56 & \\
\hline
\end{tabular}

teau, immediately followed by flow region, below room temperature. Unlike MPDI, symmetric PPDI-Urethane display a fairly long rubbery plateau extending from -70 to $+50^{\circ} \mathrm{C}$, indicating microphase separation and presence of a well-defined hard segment network. Symmetric and strongly hydrogen bonded PPDI-Urea show an extremely long rubbery plateau extending from -70 to $+200^{\circ} \mathrm{C}$, while the rubbery plateau for MPDI-Urea extends to $+100^{\circ} \mathrm{C}$. These results clearly show the dramatic influence of the strength of hydrogen bonding on modulus-temperature behavior of TPUs, together with a significant contribution from the hard segment symmetry.

Data provided in Table 5 also shows significant effect of microphase separation and strength of hydrogen bonding in the hard segments on tensile properties of model TPUs. It is especially interesting to note extremely high tensile strengths of CHDI and HDI based TPUs with very low hard segment contents, which involves just the diisocyanate backbone. These elastomeric TPUs also show higher than $800 \%$ elongation at break $[52,54]$.

In order to better understand the effect of diisocyanate chain symmetry on the nature of hydrogen bonding between urea and urethane groups in the molecular level, quantum mechanical calculations (QMC) and molecular dynamic simulations (MD) were performed $[12,55]$. As shown in Figure 11, these studies clearly showed the dramatic effect of chain symmetry in PPDI-PTMO1k urethane on the formation of a wellordered and strongly hydrogen bonded urethane hard segment network. On the other hand, formation of a very disordered hydrogen bonded hard segment network was observed in MPDI-PTMO1k urethane. These results, clearly demonstrated the significant influence of the diisocyanate symmetry on the organization of the hydrogen bonded hard segment networks in TPUs at the molecular level, which also has a direct influence on polymer morphology.

So far, we have only discussed non-chain extended TPUs as model systems, where MDI and HMDI based model polyurethanes did not show any mechanical strength at room temperature. However, in real life these diisocyanates are the main players for the preparation of TPUs, where the magic comes from the chain extension. When diol or diamine chain extenders are chemically incorporated into $\mathrm{MDI}$ and $\mathrm{HMDI}$ based TPUs to form high molecular weight hard segments, microphase separated copolymers that display excellent mechanical properties can be prepared, as discussed in Section 3.3. In fact, diol (mainly 1,4-butanediol and ethylene glycol) chain extended MDI and HMDI based TPUs constitute a great majority of the commercially available TPUs. Diamine chain extenders seem to be more popular among academic researchers since they 


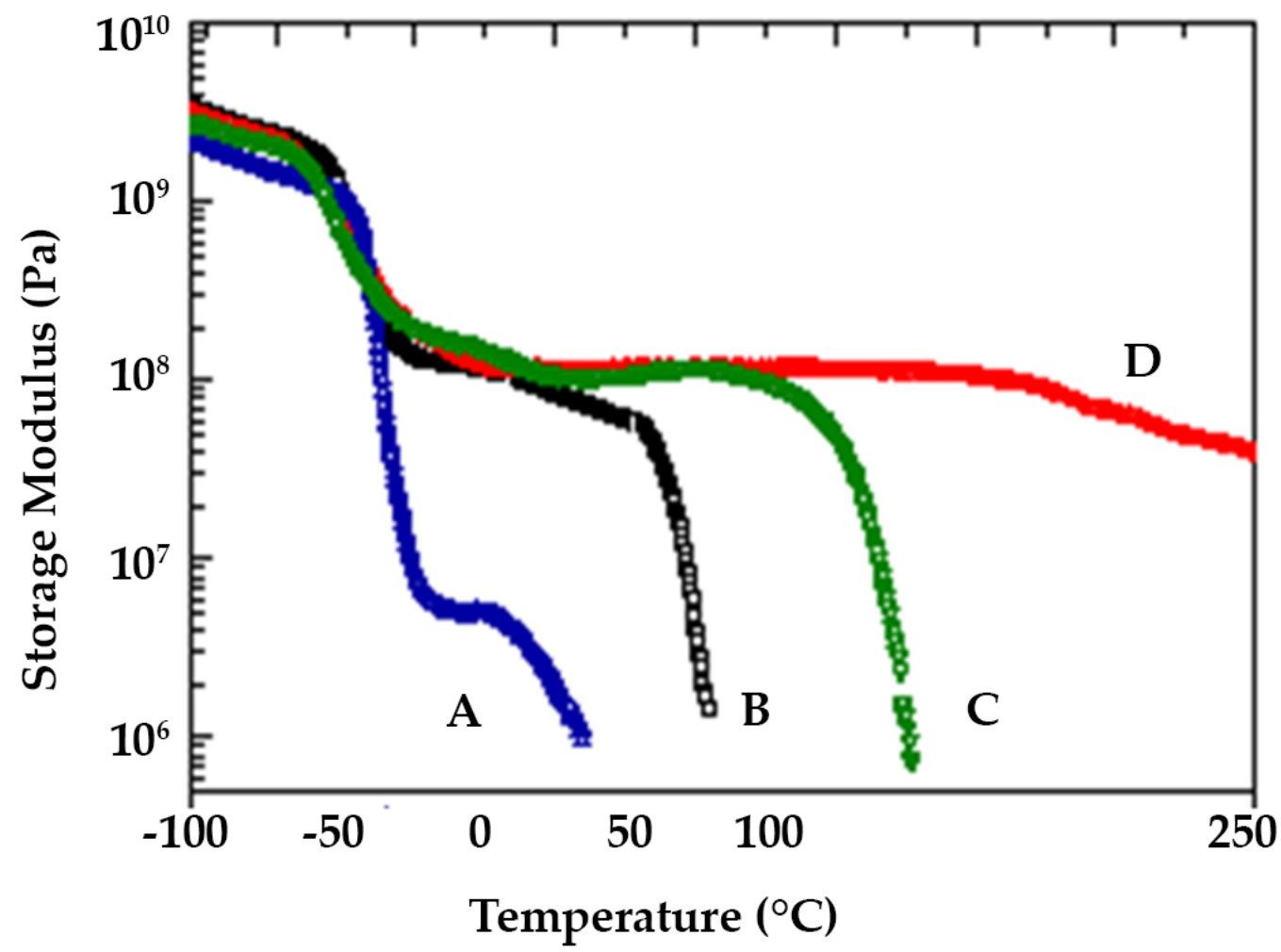

Figure 10. Modulus-temperature (DMA) curves for model TPUs prepared by stoichiometric reactions between hydroxy or amine terminated PTMO-1000 and PPDI or MPDI. (A) MPDI-Urethane, (B) PPDI-Urethane, (C) MPDI-Urea and (D) PPDI-Urea [51].

result in improved microphase separation and stronger mechanical properties, which provides an interesting platform for the investigation of structure-property behavior of these systems.

\subsection{Influence of soft segment structure, solubility pa- rameter, and average molecular weight on TPU mor- phology and properties}

As already mentioned, chemical structure, average molecular weight and the solubility parameter of the soft segments play critical roles in structure-morphologyproperty behavior of TPUs. As a rule of thumb, better microphase separation is obtained in TPUs if the solubility parameter of the soft segment is low and its molecular weight is high $[1,6]$. For example, TPUs based on polydimethylsiloxane (PDMS, $\left.\delta=15.6\left(\mathrm{~J} / \mathrm{cm}^{3}\right)^{1 / 2}\right)[44]$ and polyisobutylene $\left(\mathrm{PIB}, \delta=16.4\left(\mathrm{~J} / \mathrm{cm}^{3}\right)^{1 / 2}\right)[56,57]$ display much better microphase separation when compared with aliphatic polyethers (PEO, $\delta=20.2$ and PPO $\delta=18.9$ $\left.\left(\mathrm{J} / \mathrm{cm}^{3}\right)^{1 / 2}\right)[45]$ or aliphatic polycarbonates $(\delta=17.0(\mathrm{~J} /$ $\left.\left.\mathrm{cm}^{3}\right)^{1 / 2}\right)[58]$.
Soft segment molecular weight also has a critical influence on microphase morphology and TPU properties. For example, when PPO based polyureas with identical hard segment contents that were prepared from oligomers with molecular weights ranging from 1,000 to $11,000 \mathrm{~g} / \mathrm{mole}$ were examined, improved microphase separation and better tensile properties were observed as the PPO molecular weight increased [38]. Similar behavior was observed in PDMS-urea copolymers, prepared by using different molecular weight PDMS oligomers $(3,200$ to $32,000 \mathrm{~g} / \mathrm{mol})$ but with identical hard segment contents $[59,60]$. Two critical properties of TPU elastomers in commercial load bearing applications is their resistance to hysteresis and creep. Hysteresis is the extent of recovery to original dimensions of an elastomeric sample after deformation is released, where creep is the resistance to deformation under load. It has been shown for both PDMS [61] and PPO [38] based polyurethaneureas that as the molecular weights of the soft segments increased, hysteresis and creep decreased significantly in TPUs with similar hard segment contents. 


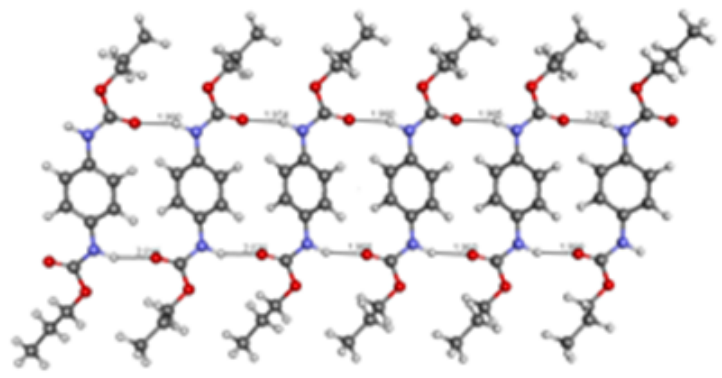

PPDI-Urethane

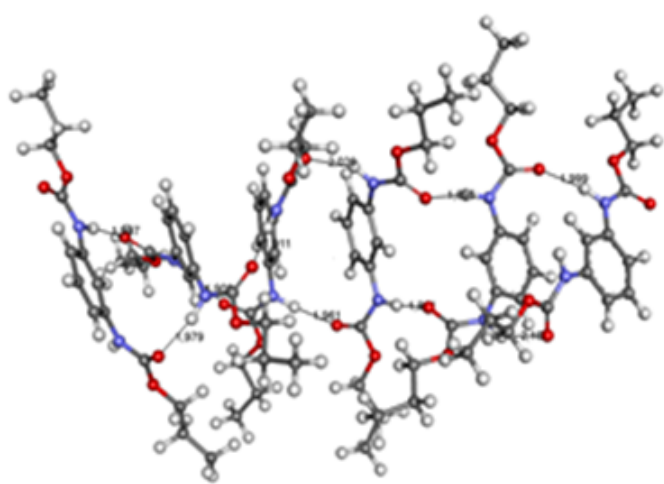

MPDI-Urethane

Figure 11. Structures of the hydrogen-bonded hexamers generated by QMC on (a) PPDI-urethane and (b) MPDI-urethane model compounds [12].

As a final note, soft segment type and structure also has significant effect on the surface properties of TPUs. This is especially important in biomedical applications of TPUs. For example, PDMS and PIB based TPUs have lower surface energies and were reported to have better biocompatibility $[5,56]$. In general PTMO, PDMS and PIB based polyurethanes were reported to display very good long term biostability, whereas aliphatic polyester (e. g. PCL) based TPUs are biocompatible but not very stable since they are biodegradable due to hydrolysis of ester linkages in their backbone.

\subsection{Influence of the hard segment structure, length, and content on TPU morphology and properties}

Strongly hydrogen bonded hard segments provide better microphase separation and higher mechanical strength to TPUs $[1,62]$. Therefore as a rule of thumb, as the hard segment content of a TPU increases, its tensile strength also increases $[1,63,64]$. One of the best examples demonstrating the influence of hard segment content on the tensile properties of TPUs are model PDMS based polyurea copolymers prepared by the stoichiometric reactions between a diisocyanate (HMDI) and amine terminated PDMS oligomers with different molecular weights [21]. As discussed already, due to significant difference between the solubility parameters of urea hard segments $\left(37.9\left(\mathrm{~J} / \mathrm{cm}^{3}\right)^{1 / 2}\right)$ [1] and PDMS (15.6 $\left.\left(\mathrm{J} / \mathrm{cm}^{3}\right)^{1 / 2}\right)$ soft segments [44], these systems display excellent microphase separation. Hard segment content of PDMS-urea copolymers based on stoichiometric reactions decrease with an increase in PDMS molecular weight. Interestingly, tensile strengths of these materials increase linearly, whereas Young's modulus values increase logarithmically with hard segment content as shown in Figure 12 [21]. Linear increase in the tensile strength as a function of hard segment content was also reported for PPO [38], PIB [56] and PTMO [62-65] based TPUs. Logarithmic increase in Young's modulus as a function of hard segment content was also observed in polyamides [45], however, no reasoning was provided for this interesting behavior.

A systematic study on the effect of hard segment structure on mechanical properties of segmented TPUs prepared from dibenzyl diisocyanate, poly(ethylene adipate) $\left(M_{n}=2000 \mathrm{~g} / \mathrm{mol}\right)$, and a series of glycol chain extenders with 2 to 6 methylene groups in their backbones [66]. Hard segment content was kept constant at about 32 percent by weight. TPU elastomers prepared using chain extenders with even carbon numbers were reported to display better mechanical properties when compared with those having an odd carbon number. This was attributed to better packing in urethane hard segments when chain extenders with even number of methylene groups are used [66]. Annealing of the copolymers for 72 hours at $70^{\circ} \mathrm{C}$ led to improvement in the ultimate tensile strengths of the copolymers. 

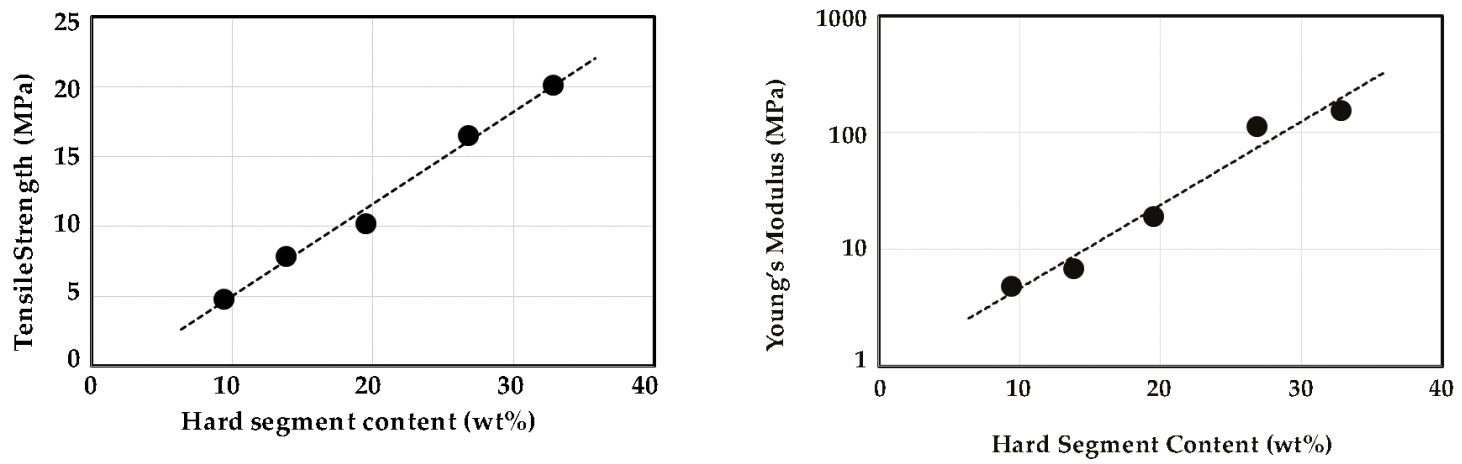

Figure 12. Linear increase in the tensile strength and logarithmic increase in the Young's modulus values of PDMS-Urea copolymers as a function of hard segment content $[21,45]$.

\subsection{Effect of the polymerization procedure on TPU} structure, morphology, and properties

Two different synthetic procedures are mainly used for the preparation of segmented TPUs [1, 3-5]. In the first procedure, which is called "one-shot method", all reac- tants, the diisocyanate, soft segment oligomer, the diol chain extender and catalyst (if needed) are mixed together at the desired stoichiometric amounts and reacted in a batch process, in bulk. Although one-shot process is simple, since chemical reactions are random in natu-

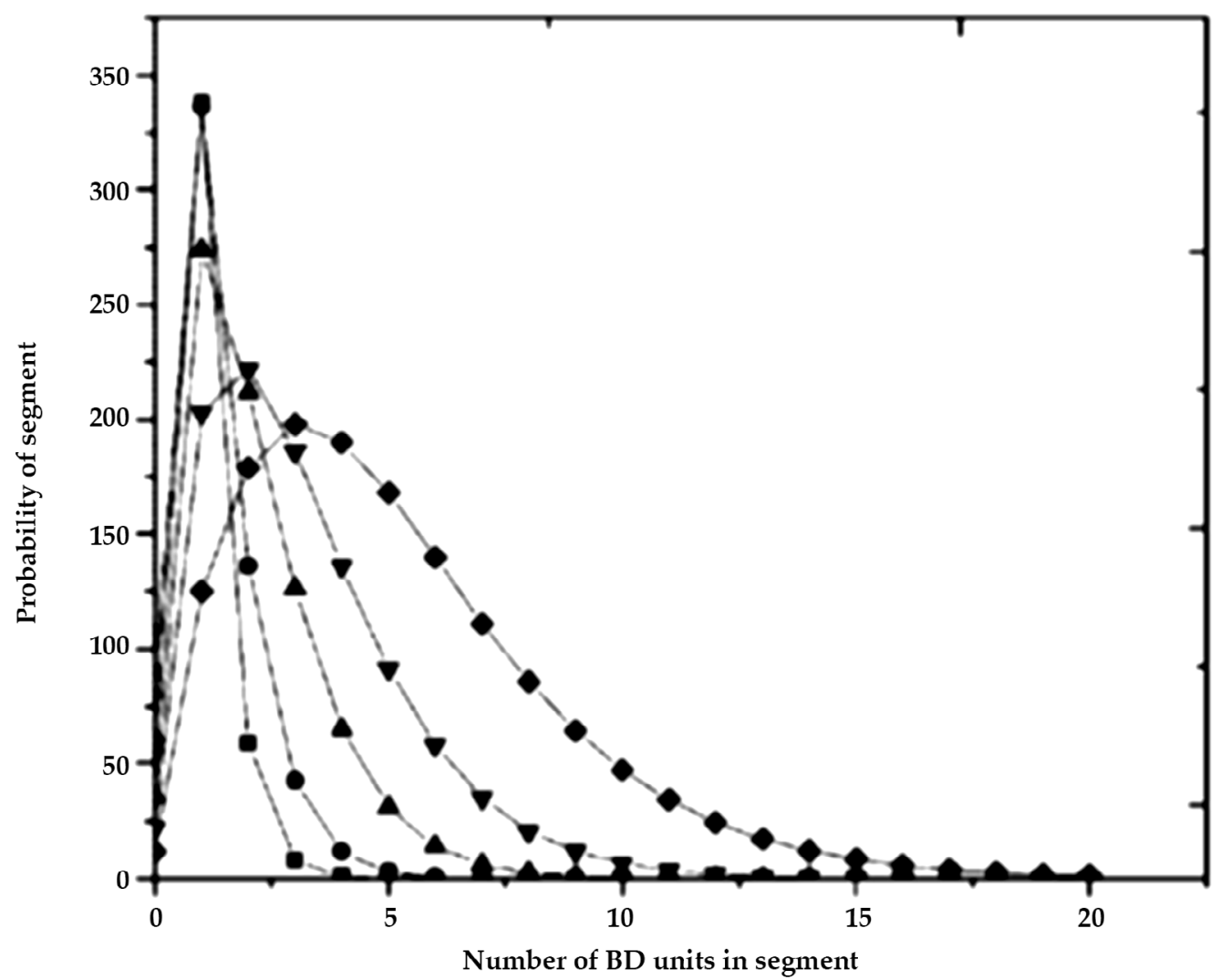

Figure 13. Normalized weight average hard segment sequence length distribution for segmented polyurethanes based on MDI and BD with hard segment contents of $(\boldsymbol{\bullet}) 30,(\bullet) 35,(\boldsymbol{\Delta})$ 40, ( $) 45$ and (•) 52 percent by weight [58]. 
re, it does not provide a precise control over the length and distribution of the hard segments in TPU backbone, since isocyanate may or will not be selective in reacting with the soft segment or the chain extender. Second method, called the "prepolymer method" consists of two steps and provides better control of the hard segment structure. In the first step excess diisocyanate is reacted with the soft segment oligomer, in bulk or in solution, to form an isocyanate terminated "prepolymer". In the second step called "chain extension", the prepolymer is reacted with an organic diol or diamine to form the hard segments and increase the overall molecular weight of TPU. Although this method provides some control on the molecular weights of the hard segments formed, there is still a distribution of HS chain lengths as a function of hard segment content as shown in Figure 13 [58].

An important advice regarding the prepolymer formation reactions is the need to determine the isocyanate content of the prepolymer by titration $[3,9]$ and adjust the stoichiometric amount of the chain extender to be used accordingly. This point is usually overlooked by researchers. However, since the side reactions discussed in Section 2.2 consume extra amount of isocyanate, without titration the reaction stoichiometry will be upset. As well-known, in step-growth polymerizations it is critical to have one-to-one stoichiometry between the reactive groups in order to obtain high molecular weight polymers [27].

\subsection{Effect of thermal history on TPU morphology and properties}

In general, thermal history has a significant effect on the morphology of multiphase copolymers. It is especially critical for TPUs, since at high temperatures, the hydrogen bonding between the urethane or urea hard segments weakens, leading to phase mixing. Of course, this is beneficial during melt processing or injection molding to produce well-defined articles. When the TPU is cooled down from melt, microphase separation takes place slowly, until the system reaches equilibrium morphology. Depending on the parameters discussed already, such as soft segment solubility parameter and molecular weight, hard segment type (urea versus urethane) and content, reaching to the equilibrium morphology requires different time periods, from very short to very long.

Time dependent morphology development in various model polyurethanes and polyureas discussed already in Section 3.1 has been investigated by FTIR, AFM and SAXS studies. FTIR is a simple but powerful technique to follow morphology development in TPUs, since significant peak shifts are observed in hydrogen bonded urethane carbonyl $(\mathrm{C}=\mathrm{O})$ and amide $(\mathrm{N}-\mathrm{H})$ peaks [67] as shown in Table 6.

As can be seen in Table 6, while non-hydrogen bonded $\mathrm{C}=\mathrm{O}$ group in an ester or urethane linkage absorbs in 1740-1750 $\mathrm{cm}^{-1}$ range, depending on the extent and strength of hydrogen bonding, it shifts significantly

Table 6. Characteristic IR absorption frequencies for $\mathrm{C}=\mathrm{O}$ and $\mathrm{N}-\mathrm{H}$ groups in segmented polyurethanes and polyureas.

\begin{tabular}{ccc}
\hline Group & Mode & Frequency $\left(\mathrm{cm}^{-1}\right)$ \\
\hline $\mathrm{N}-\mathrm{H}$ & Free & $3445-3450$ \\
\hline $\mathrm{N}-\mathrm{H}$ & $\mathrm{N}-\mathrm{H} \ldots . . \mathrm{N}-\mathrm{H}$ & $3315-3340$ \\
\hline $\mathrm{N}-\mathrm{H}$ & $\mathrm{N}-\mathrm{H} \ldots . . \mathrm{O}$ (ether) & $3260-3290$ \\
\hline $\mathrm{C}=\mathrm{O}$ (urethane) & Free & $1740-1750$ \\
\hline $\mathrm{C}=\mathrm{O}$ (urethane) & $\mathrm{C}=\mathrm{O} . \ldots . \mathrm{H}-\mathrm{N}$ & $1703-1710$ \\
\hline $\mathrm{C}=\mathrm{O}$ (urethane) & $\mathrm{C}=\mathrm{O} . \ldots . \mathrm{H}-\mathrm{N}$ & $1680-1695$ (ordered) \\
\hline $\mathrm{C}=\mathrm{O}$ (urea) & Free & $1690-1700$ \\
\hline $\mathrm{C}=\mathrm{O}$ (urea) & $\mathrm{C}=\mathrm{O} . \ldots . \mathrm{H}-\mathrm{N}$ & $1660-1670$ (disordered) \\
\hline $\mathrm{C}=\mathrm{O}$ (urea) & $\mathrm{C}=\mathrm{O} . \ldots . \mathrm{H}-\mathrm{N}$ & $1630-1645$ (ordered) \\
\hline $\mathrm{NH}-\mathrm{C}=\mathrm{O}$ & Amide II & $1540-1560$
\end{tabular}




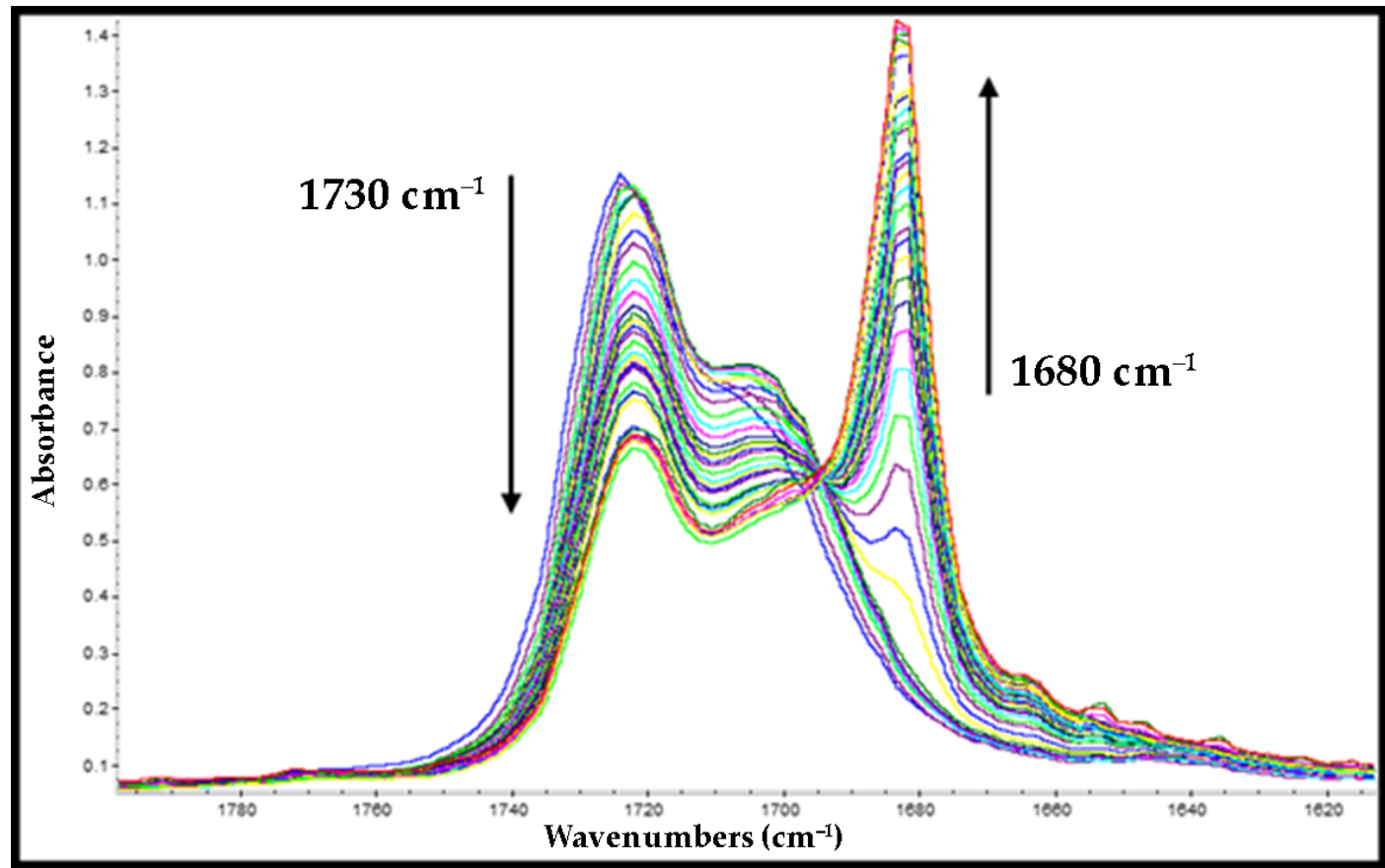

Figure 14. Time dependent FTIR spectra of carbonyl region for HDI-PTMO1k model polyurethane cooled at room temperature from melt at $105^{\circ} \mathrm{C}[54]$.

down to $1680-1695 \mathrm{~cm}^{-1}$. The shift is more dramatic in strongly hydrogen bonded urea groups as can be seen in Table 6. As a result, by following the change in peak positions and absorbance values in FTIR spectroscopy, one can easily follow the development of hydrogen bonded hard segment network in TPUs, which provides an indirect but reliable measure of the microphase separation.

It has been shown that for model, non-chain extended PPDI-PTMO1k polyurethane about 1 week was necessary to reach equilibrium morphology when cooled at room temperature from $60-70^{\circ} \mathrm{C}$ melt [68]. On the ot- her hand for CHDI-Urethane it was much shorter to reach the equilibrium morphology, about 4 hours, when cooled at room temperature from melt [67]. As a general example, time dependent intensity changes in the carbonyl peaks for HDI-PTMO1k model polyurethane, cooled at room temperature from melt are provided in Figure 14 [47].

As can be seen in Figure 14 in melt at $105^{\circ} \mathrm{C}$, TPU is completely mixed and there is no strongly hydrogen bonded $\mathrm{C}=\mathrm{O}$ absorption at $1680 \mathrm{~cm}^{-1}$, while there is a strong non-hydrogen bonded $\mathrm{C}=\mathrm{O}$ peak at $1730 \mathrm{~cm}^{-1}$.

Table 6. Characteristic IR absorption frequencies for $\mathrm{C}=\mathrm{O}$ and $\mathrm{N}-\mathrm{H}$ groups in segmented polyurethanes and polyureas.

Diisocyanate
Time to reach equilibrium morphology (hr)

\begin{tabular}{cc}
\hline PPDI & 1 \\
\hline MDI & 2 \\
\hline TDI & 10 \\
\hline MPDI & 150 \\
\hline
\end{tabular}


During cooling at room temperature $1730 \mathrm{~cm}^{-1}$ peak intensity decreases, while $1680 \mathrm{~cm}^{-1}$ peak intensity increases as a function of time and reaches to a constant value after about 7200 minutes or 5 days [67]. As expected, model polyureas reach equilibrium morphology much faster than polyurethanes, however time to reach equilibrium still shows a strong dependence on the symmetry of the diisocyanate, as shown in Table 7 [69].

\section{Concluding remarks}

Polyurethanes constitute one of the most important classes of polymeric materials. This is mainly due to availability of a very large number of starting materials that allows tailor design and synthesis of polyurethanes with a wide range of properties, ranging from adhesives to high strength plastics. Polyurethanes can be divided in two subgroups, PU foams (rigid and flexible) and elastomers. PU foams command most of the market share. Rigid PU foams find applications as insulation panels in construction and appliance sector, in packaging and as adhesives and sealants. Flexible PU foams are mainly used in bedding, furniture and in transportation as seating. Elastomers on the other hand find applications as textile fibers, artificial leather, membranes, paints and coatings, footwear, sporting goods, and specialty medical products.

In this short review we tried to discuss critical physical and chemical parameters that have a strong influence on the morphology and properties of polyurethanes. These mainly included (i) type, nature, and molecular weight of the soft and hard segments, (ii) chemical structure and composition of the copolymer, (iii) synthetic method followed, and (iv) the thermal history of the polymer.

We hope this review article on polyurethanes, which was written to celebrate the $100^{\text {th }}$ anniversary of Polymer Science, will be useful to those who are newcomers to the field, but also to the experienced researchers to better understand the structure-property behavior of these interesting materials and tailor-design novel structures for various applications.

\section{References}

1. I. Yilgör, E. Yilgör, G.L. Wilkes, Critical parameters in designing segmented polyurethanes and their effect on morphology and properties: A comprehensive review Polymer, 58 (2015) A1-A36.

2. C.S. Schollenberger, H. Scott, G.H. Moore, Polyurethane VC, a virtually cross-linked elastomer, Rubber World, 137 (1958) 549-555.

3. J.H. Saunders, K.C. Frisch, Polyurethanes: Chemistry and technology, 1962, New York: Interscience Publishers.

4. C. Hepburn, Polyurethane elastomers, Second edition ed. 1992, London, UK: Elsevier Science Publishers.

5. N.M.K. Lambla, K.A. Woodhouse, S.L. Cooper, Polyurethanes in biomedical applications, 1998, Boca Raton, FL, USA: CRC Press.

6. P. Krol, Synthesis methods, chemical structures and phase structures of linear polyurethanes. Properties and applications of linear polyurethanes in polyurethane elastomers, copolymers and ionomers, Prog. Mater. Sci., 52 (2007) 915-1015.

7. E. Delebecq, et al., On the versatility of urethane/urea bonds: Reversibility, blocked isocyanate, and non-isocyanate polyurethane, Chem. Rev., 113 (2013) 80-118.

8. R. Herrington, K. Hock, Flexible polyurethane foams, 1991, USA: Dow Plastics.

9. I. Yilgör, J.E. McGrath, Effect of catalysts on the reaction between a cycloaliphatic diisocyanate (h-mdi) and normalbutanol, J. Appl. Polym. Sci., 30 (1985)1733-1739.

10. M. Sato, The rate of reaction of isocyanates with alcohols, II. Journal of Organic Chemistry, 1962. 27(3): p. 819-825.

11. E. Yilgör, I. Yilgor, E. Yurtsever, Hydrogen bonding and polyurethane morphology. I. Quantum mechanical calculations of hydrogen bond energies and vibrational spectroscopy of model compounds, Polymer, 43 (2002) 6551-6559.

12. S. Sami, et al., Understanding the influence of hydrogen bonding and diisocyanate symmetry on the morphology and properties of segmented polyurethanes and polyureas: Computational and experimental study, Polymer, 55 (2014) 4563-4576.

13. O. Bayer, Verfahren zur Herstellung von Polyurethanen bzw. Polyharnstoffen. 1938: Germany.

14. O. Bayer, Das Di-Isocyanat-Polyadditionsverfahren (Polyurethane). Angew. Chem. Int. Ed., 59 (1947) 257-272.

15. M.E. Hermes, Enough for One Lifetime: Wallace Carothers, Inventor of Nylon. . 1996, Washington DC, USA: ACS.

16. D.H. Keifer, The Establishment of Modern Polymer Science By Wallace H. Carothers 2000, USA: ACS

17. T. Hentschel, H. Munstedt, Kinetics of the molar mass decrease in a polyurethane melt: a rheological study, Polymer, 42 (2001) 3195-3203.

18. G. Woods, The ICl polyurethanes Book. 1990, USA: John Wiley and Sons.

19. I. Yilgör, et al., Siloxane-urea segmented co-polymers, 1. Synthesis and characterization of model polymers from mdi and alpha,omega-bis(aminopropyl)polydimethylsiloxane, Polym. Bull., 8 (1982) 535-542.

20. E. Yilgör, et al., Isopropyl alcohol: An unusual, powerful, 'green' solvent for the preparation of silicone-urea copolymers with high urea contents, Polymer, 44 (2003) 7787-7793. 
21. E. Yilgör, I. Yilgor, Hydrogen bonding: A critical parameter in designing silicone copolymers, Polymer, 42 (2001) 7953 7959.

22. G. Benrendt, B.W. Naber, The chemical recycling of polyurethanes, Journal of the University of Chemical Technology and Metallurgy, 44 (2009) 3-23.

23. Recycling of polyurethane foams. 2018, USA: William Andrew Applied Science Publishers, Elsevier.

24. Polyurethane market. 2020; Available from: https://www. marketsandmarkets.com/Market-Reports/polyurethanemarket-151784541.html

25. Global Polyurethane Market (2019 to 2023). 2020; Available from: https://www.businesswire.com/news/ home/20200320005325/en/Global-Polyurethane-Market2019-2023---Identify.

26. Polyurethane Market Analysis Report By Product (Rigid Foam, Flexible Foam, Coatings), By Application (Furniture \& Interiors, Construction, Automotive), And Segment Forecasts, 2019 - 2025. 2020; Available from: https://www. grandviewresearch.com/industry-analysis/polyurethanepu-market.

27. P.J. Flory, Principles of Polymer Chemistry. 1953, Ithaca, USA: Cornell University Press.

28. J.M. Castro, C.W. Macosco, Studies of mold filling and curing in the reaction injection-molding process, AIChE J., 28 (1982) 250-260.

29. R.E. Camargo, et al., Phase-separation studies in rim polyurethanes catalyst and hard segment crystallinity effects, Polymer, 26 (1985) 1145-1154.

30. K. Dusek, M. Spirkova, I. Havlicek, Network formation of polyurethanes due to side reactions, Macromolecules, 23 (1990) 1774-1781.

31. K. Dusek, M. Spirkova, M. Ilavsky, Network formation in polyurethanes due to allophanate and biuret formation gel fraction and equilibrium modulus, Makromol. Chem., Macromol. Symp., 45 (1991) 87-95.

32. P.J. Flory, Thermodynamics of high polymer solutions, J. Chem. Phys., 10 (1942) 51-61.

33. M.L. Huggins, Thermodynamic properties of solutions of long-chain compounds, Ann. N. Y. Acad. Sci., 43 (1942) 1-32.

34. L.M. Robeson, Polymer Blends: A Comprehensive Review. 2007, Munich, Germany: Carl Hanser Verlag. 687.

35. L. Leibler, Theory of microphase separation in block copolymers, Macromolecules, 13 (1980) 1602-1617.

36. D.W.V. Krevelen, Properties of Polymers. 1990, Amsterdam, Netherlands: Elsevier Science Publishers.

37. F. E. Bailey, J. and J.V. Koleske, Poly(ethylene oxide). 1976, New York, USA: Academic Press.

38. S.P. Ertem, et al., Effect of soft segment molecular weight on tensile properties of poly(propylene oxide) based polyurethaneureas, Polymer, 53 (2012) 4614-4622.

39. P. Dreyfuss, Poly(tetrahydrofuran). 1982, New York, USA Gordon and Breach Science Publishers.

40. M.A. Woodruff, D.W. Hutmacher, The return of a forgotten polymer-Polycaprolactone in the 21st century, Prog. Polym. Sci., 35 (2010) 1217-1256

41. E. Yilgör, I. Yilgör, Silicone containing copolymers: Synthesis, properties and applications, Prog. Polym. Sci., 39 (2014) 1165-1195.

42. D. Tyagi, et al., Siloxane-urea segmented co-polymers, 2 Investigation of mechanical-behavior, Polym. Bull., 8 (1982) 543-550.

43. I. Yilgör, et al., Segmented organosiloxane copolymers, 1. Synthesis of siloxane urea copolymers, Polymer, 25 (1984) 1800-1806
44. I. Yilgör, J.E. McGrath, Polysiloxane containing copolymers a survey of recent developments, Adv. Polym. Sci., 86 (1988) 1-86.

45. E. Yilgör, et al., Comparison of hydrogen bonding in polydimethylsiloxane and polyether based urethane and urea copolymers, Polymer, 41 (2000) 849-857.

46. A. Campanella, L.M. Bonnaillie, R.P. Wool, Polyurethane foams from soyoil-based polyols, J. Appl. Polym. Sci., 112 (2009) 2567-2578

47. X.D. Zhang, et al., Role of silicone surfactant in flexible polyurethane foam, J. Colloid Interface Sci., 215 (1999) 270279.

48. D.K. Chattopadhyay, K.V.S.N. Raju, Structural engineering of polyurethane coatings for high performance applications, Prog. Polym. Sci., 32 (2007) 352-418.

49. I. Yilgör, E. Yilgör, Hydrophilic polyurethaneurea membranes: influence of soft block composition on the water vapor permeation rates, Polymer, 40 (1999) 5575-5581.

50. D.B. Klinedinst, et al., Structure - property behavior of new segmented polyurethanes and polyureas without use of chain extenders, Rubber Chem. Technol., 78 (2005) 737-753.

51. J.P. Sheth, et al., Role of chain symmetry and hydrogen bonding in segmented copolymers with monodisperse hard segments, Polymer, 46 (2005) 7317-7322.

52. S. Das, et al., Effect of symmetry and $\mathrm{H}$-bond strength of hard segments on the structure-property relationships of segmented, nonchain extended polyurethanes and polyureas, J. Macromol. Sci. Part B Phys., 46 (2007) 853-875.

53. E. Yildirim, et al., Temperature-dependent changes in the hydrogen bonded hard segment network and microphase morphology in a model polyurethane: Experimental and simulation studies, J. Polym. Sci., Part B: Polym. Phys., 56 (2018) 182-192.

54. I. Yilgör, E. Yilgör, Structure-morphology-property behavior of segmented thermoplastic polyurethanes and polyureas prepared without chain extenders, Polym. Rev., 47 (2007) 487-510.

55. E. Yildirim, et al., Multiscale modeling of the morphology and properties of segmented silicone-urea copolymers. J. Inorg. Organomet. Polym. Mater., 22 (2012) 604-616.

56. S.K. Jewrajka, et al., Polyisobutylene-based polyurethanes, ii. Polyureas containing mixed pib/ptmo soft segments, J. Polym. Sci., Part A: Polym. Chem., 47 (2009) 2787-2797.

57. J. Kang, et al., PIB-based polyurethanes, IV. The morphology of polyurethanes containing soft co-segments, J. Polym. Sci., Part A: Polym. Chem., 47 (2009) 6180-6190.

58. R. Hernandez, et al., A comparison of phase organization of model segmented polyurethanes with different intersegment compatibilities. Macromolecules, 41 (2008) 9767-9776.

59. J.P. Sheth, et al., Influence of system variables on the morphological and dynamic mechanical behavior of polydimethylsiloxane based segmented polyurethane and polyurea copolymers: a comparative perspective, Polymer, 45 (2004) 6919-6932.

60. I. Yilgör, et al., Contribution of soft segment entanglement on the tensile properties of silicone-urea copolymers with low hard segment contents, Polymer, 50 (2009) 4432-4437.

61. I. Yilgör, et al., Influence of soft segment molecular weight on the mechanical hysteresis and set behavior of siliconeurea copolymers with low hard segment contents, Polymer, 52 (2011) 266-274

62. A. Aneja, G.L. Wilkes, A systematic series of 'model' PTMO based segmented polyurethanes reinvestigated using 
atomic force microscopy, Polymer, 44 (2003) 7221-7228.

63. R.M. Versteegen, R.P. Sijbesma, E.W. Meijer, Synthesis and characterization of segmented copoly(ether urea)s with uniform hard segments, Macromolecules, 38 (2005) 3176 3184.

64. R.M. Versteegen, et al., Properties and morphology of segmented copoly(ether urea)s with uniform hard segments, Macromolecules, 39 (2006) 772-783.
65. D. De, R.J. Gaymans, Thermoplastic polyurethanes with TDIbased monodisperse hard segments. Macromol. Mater. Eng., 294 (2009) 405-413.

66. C. Prisacariu, E. Scortanu, Influence of the type of chain extender and urethane group content on the mechanical properties of polyurethane elastomers with flexible hard segments, High Perform. Polym., 23 (2011) 308-313.

67. I. Yilgör, et al., FTIR investigation of the influence of diisocyanate symmetry on the morphology development in model segmented polyurethanes, Polymer, 47 (2006) 41054114.

68. J.P. Sheth, et al., Time-dependent morphology development in a segmented polyurethane with monodisperse hard segments based on 1,4-phenylene diisocyanate, Macromolecules, 38 (2005) 10074-10079.

69. I. Yilgör, et al., Time-dependent morphology development in segmented polyetherurea copolymers based on aromatic diisocyanates, J. Polym. Sci., Part B: Polym. Phys., 47 (2009) 471-483. 